\title{
Understanding of Factors Influencing Happiness of Middle-Aged Women in Korea Based on Maslow's Hierarchy of Needs
}

\author{
Su Jin Kim ${ }^{1}$ and Myung-Haeng Hur ${ }^{2} \bowtie$ \\ ${ }^{1}$ Department of Nursing, Chung Cheong University, Cheongju, Republic of Korea \\ ${ }^{2}$ Department of Nursing, Eulji University, Daejeon, Republic of Korea
}

Objective Middle-aged women experience a lot of events of physical changes and various mental conflicts. The purpose of this study is to determine variables related to happiness, and to make and verify the model for happiness of middle-aged women.

Methods We constructed conceptual model for happiness of middle-aged women in Korea, based on Maslow's hierarchy of needs. This model consisted of three exogenous variables (health status, financial distress, and social support) and three endogenous variables (selfesteem, positive thinking, and happiness). For middle-aged women in Korea, we returned 442 questionnaires of 460 participants.

Results Model fit of the modified model was satisfied; $\chi^{2}=102.108, \mathrm{GFI}=0.959, \mathrm{CMIN} / \mathrm{DF}=2.917, \mathrm{RMSEA}=0.068, \mathrm{AGFI}=0.922$, $\mathrm{CFI}=0.977$, SRMR $=0.0368$. Happiness was explained by $82 \%$ through health status, financial distress, social support, self-esteem, and positive thinking. As Maslow's hierarchy of needs, happiness of middle-aged women is related to basic needs (health status, financial distress, and social support), psychological needs (self-esteem and positive thinking) and self-fulfillment needs (happiness).

Conclusion Our study shows that it is required intervention for meeting basic factor such as health status, financial distress and social support in order to increase happiness of middle-aged women.

Psychiatry Investig 2019;16(7):539-546

Key Words Women, Happiness, Social support, Health status.

\section{INTRODUCTION}

As the life span increases, the middle age has become a major period to deciding the life of old age. ${ }^{1}$ The middle age is the turning point of life that can re-assess women's lives. ${ }^{2}$ This period also acts as the bridge that can have an important impact on the rest of their life. In middle age, women experience the changes and confusion in various aspects of life. ${ }^{3,4}$ Physically, they are increasingly interested in issues related to health because their body has menopause and gets weaker. Mentally, women are confused about their role in family. It is important for middle-age women to satisfy physical and mental life. ${ }^{5}$ These satisfactions have much to do with happiness, which is a good measure to judge successful people and society. ${ }^{6}$

Received: January 23, 2019 Revised: March 11, 2019

Accepted: April 25, 2019

$\triangle$ Correspondence: Myung-Haeng Hur, PhD

Department of Nursing, Eulji University, 77 Gyeryong-ro 771beon-gil, Junggu, Daejeon 34824, Republic of Korea

Tel: +82-42-259-1714, Fax: +82-42-259-1709, E-mail: mhhur@eulji.ac.kr

(a) This is an Open Access article distributed under the terms of the Creative Commons Attribution Non-Commercial License (https://creativecommons.org/licenses/bync/4.0) which permits unrestricted non-commercial use, distribution, and reproduction in any medium, provided the original work is properly cited.
Happiness is not just a state that negative emotion is removed, but a peak experience of self-realization that is accomplished by maximizing one's own abilities. ${ }^{7}$ The happiness of middle-aged women affects their welfare and psychological well-being directly. ${ }^{8}$ Happiness can expand cognitive and emotional aspects. It makes the person's physical and psychological aspects available fully. In other words, happiness is the best value that people can enjoy in their own life through the manifestation of possibilities and positive emotions. ${ }^{9}$

\section{Factors influencing happiness of middle-aged women}

Various factors affect happiness of middle-aged women internally and externally. Internal factors related to psychological condition include attitude, commitment, positive thinking, self-esteem and so on. Among these, positive thinking and self-esteem are attracting attention as an important factors influencing happiness. ${ }^{10}$ External factors related to external environment include economic power, education, income, health status, social support and so on. Among these, health status, financial distress, and social support have been reported to affect the happiness of middle-aged women. These health conditions are closely related to the happiness, and it 
is reported that the better the health condition, the more positive the subjective perception of life. ${ }^{11}$

Positive thinking is the social emotional attitude such as life satisfaction and optimistic potentiality. People with high positive thinking has high self-efficacy because they have generally a high level of happiness and self-esteem in life, and because they are proficient in social relations and expressive emotions. ${ }^{12}$ As positive thinking is increased, emotional and psychological well-being is increased, and satisfaction for life is also increased. ${ }^{9}$

Self-esteem is the positive acceptance, and the evaluation of one's own abilities and values. ${ }^{13}$ High levels of self-esteem in middle-aged women are associated with satisfactory psychological well-being. ${ }^{14}$ It enhances happiness by acting as an important coping factor in various crisis situations facing middle age. $^{15}$

Health status is the balance of subjective health perceptions of physical, mental and social health. ${ }^{16}$ It is a key concept explaining happiness because it enables a variety of physical and mental functions to perform. Also, as the frequency of positive interactions with colleagues based on physical health is increased, self-esteem and happiness are increased. ${ }^{17}$

Financial distress is the economic imbalance that reduces satisfaction with life and affects happiness. Also, those who experienced positive economic situation showed higher happiness. ${ }^{18}$ However, if they are above a certain income level, they no longer affect happiness. Therefore, although the average income increases, happiness does not always increase. In general, as the age of middle-aged women increases, economic stress increases due to income restrictions, retirement preparation, retirement, spouse retirement, admission of children and marriage of children. Therefore, the economic stress decreased with the stable and regular income of middle-aged women, and the lower the economic stress, the higher the level of happiness of women. ${ }^{19}$

Social support refers to the degree of trust and recognition from family members, friends, and others through relationships. ${ }^{20}$ Social support and positive interpersonal relations have been shown to improve the sense of well-being through emotional fulfillment. ${ }^{21}$ The relationship between family and acquaintances, such as social support, is caring and respectful, and positive support of the surroundings that can confirm their value. In addition, expanding social relations reduces negative emotions such as loss feelings and increases belief in oneself. ${ }^{4}$ High social support elevates self-esteem and improves happiness. ${ }^{22}$

\section{Conceptual framework}

There are various theories related to happiness. The desire fulfillment theory is that people have happiness when they have something like money, health, honor, and knowledge. However, the theory has a limit that does not increase the happiness when possessing a certain degree or more. ${ }^{23}$ Maslow's hierarchy of needs explain that self-realization and happiness are the stage of maturity of personality, ant that they were gradually satisfied from basic desire to psychological desire by stages. ${ }^{7}$ This theory clarified the process by which humans enjoy happiness by helping them realize hidden potential and self-realization. ${ }^{24}$ It is suitable for explaining the happiness of a middle-aged woman who satisfies psychological needs in stages after basic external factors are satisfied.

Therefore, this study selected Maslow's hierarchy of needs ${ }^{7}$ as theory for happiness of middle-aged women in Korea. Health status, financial distress and social support were found to be positive factors affecting happiness by changing positive thinking and self-esteem. ${ }^{25,26}$ Psychological variables such as positive thinking and self-esteem have a direct and powerful influence on happiness. ${ }^{27}$

Based on Maslow's hierarchy of needs, this study constructed conceptual model and proposed hypothetical model for happiness of middle-aged women (Figure 1). This model consisted of 3 exogenous variables, 3 endogenous, and 11 measured variables. As Basic Needs, health status has 3 variables (physical health, mental health, and social health), financial distress has 1 variable (financial distress), and social support has 2 variables (family, significant other). As Psychological Needs, self-esteem has a variable (self-esteem) and positive thinking has 2 variables (subjective satisfaction and goal pursuit). As Self-fulfillment Needs, happiness has 2 variables (positive factor and negative factor).

\section{Study's purpose}

This paper analyzes the relationship related to happiness of middle-aged women in Korea using various factors: positive thinking, self-esteem, social support, financial distress, and health status. The purpose of this study is to investigate the inner and outer factors for happiness of middle-aged women based on Maslow's hierarchy of needs. The theoretical framework of this study explained human happiness as self-realization and growth theory based on human desire. ${ }^{24}$ The theory distinguishes human desire satisfaction in three stages. The first is stage of satisfying the basic needs related to the external physical situation. The next is stage of satisfying the psychological needs related to the internal achievement. Final stage is the self-fulfilling desire fulfillment stage of experiencing the happiness by successively satisfying the self-realization need. This study investigated the influence variables of middle-aged women related to happiness and found a direct and indirect relationship among middle-aged women. Furthermore, we will provide the framework and basic data 


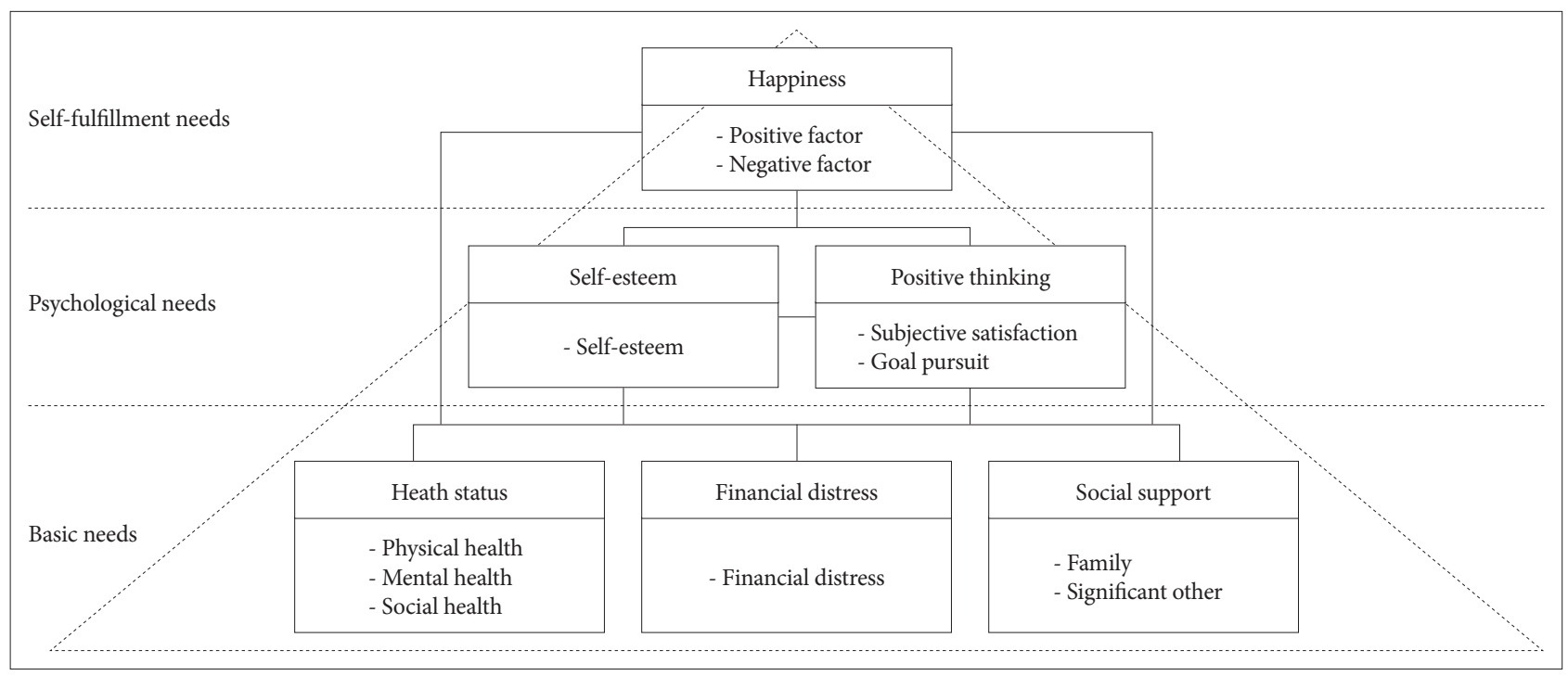

Figure 1. Conceptual model based on Maslow's hierarchy of needs.

needed to develop nursing intervention strategies to enhance the happiness of middle-aged women.

\section{METHODS}

\section{Participants}

Participants were middle-aged women between the ages of 40 and 65 . They agreed to a written explanation that they would understand the purpose and content of the study and participate this study. Data collection was conducted for middleaged women living in four metropolitan cities and other cities in Korea from February 5 to April 5, 2015. A total of 460 questionnaires were distributed in this study and 442 copies were collected (response rate $=96 \%$ ). A total of 420 copies were used for final analysis except for 22 insufficient data.

\section{Instrumentals}

Happiness was measured using The Oxford Happiness Questionnaire, ${ }^{28}$ translated in Korea. ${ }^{29}$ This measurement tool contains 29 questions and rated on a 6-point Likert scale. Cronbach $\alpha$ of this study was 0.91 whereas original author reported Cronbach $\alpha$ of 0.90. A higher score indicates more happiness.

Positive thinking was measured using Positive Thinking Scale. ${ }^{30}$ This measurement tool contains 18 questions and rated on a 5-point Likert scale. Cronbach $\alpha$ of this study was 0.92 whereas original author reported Cronbach $\alpha$ of 0.88 . A higher score indicates more positive thinking.

Self-esteem was measured using Rosenberg Self Esteem Scale (RSES), ${ }^{13}$ translated in Korea. ${ }^{31}$ This measurement tool contains 10 questions and rated on a 4-point Likert scale. Cron- bach $\alpha$ of this study was 0.82 whereas original author reported Cronbach $\alpha$ of 0.85 . A higher score indicates a higher self-esteem.

Social support was measured using Multi-dimensional Scale of Perceived Social Support (MSPSS), ${ }^{20}$ translated in Korea. ${ }^{32}$ This measurement tool contains 12 questions and rated on a 7 -point Likert scale. Cronbach $\alpha$ of this study was 0.94 whereas original author reported Cronbach $\alpha$ of 0.86 . A higher score indicates more social support.

Financial distress was measured using In Charge Financial Distress/ Financial Well-Being Scale (IFDFW), ${ }^{33}$ translated in Korea. ${ }^{34}$ This measurement tool contains 8 questions and rated on a 10-point Likert scale. Cronbach $\alpha$ of this study was 0.95 whereas original author reported Cronbach $\alpha$ of 0.95 . A higher score indicates less financial distress.

Health status was measured using Total Health Index (THI). ${ }^{35}$ This measurement tool contains 10 questions and rated on a 5 -point Likert scale. Cronbach $\alpha$ of this study was 0.95 whereas original author reported Cronbach $\alpha$ of 0.91. A high score for any factor indicates that health status is not good. Therefore, in the analysis, negative score means that health has a positive effect.

\section{Data analysis}

This study performed structural equation model (SEM) using SPSS version 21.0 and AMOS 21.0 (IBM Corp., Armonk, NY, USA). We selected fit indices as follows: the relative chisquare (CMIN/DF; $<3$ ), the goodness of fit index (GFI; $\geq 0.9$ ), the adjusted goodness of fit index (AGFI; $\geq 0.9$ ), the comparative fit index (CFI; $\geq 0.9$ ), standardized root mean residual (SRMR; $\leq 0.08$ ), and root mean square error of approxima- 
tion (RMSEA; 0-0.10).

\section{Ethical considerations}

This study was approved by the Institutional Review Board of Eulji University in Korea (EU15-01). Participants were informed of the purpose of the survey and agreed with our questionnaire.

\section{RESULTS}

\section{Preliminary analyses}

The mean age of participants was $51.8 \pm 7.3($ mean \pm SD) years and their mean duration of marriage was $26.2 \pm 9.8$ (mean \pm SD) years. Most of them were married with 392 (93.3\%). For the level of education, 200 (47.6\%) graduated from high school, 148 (35.2\%) from university, and 72 (17.2\%) from middle school or less. $300(71.4 \%)$ had religion and $284(67.6 \%)$ had the occupation. In marriage, 181 (43.1\%) were satisfied and 52 (12.4\%) were dissatisfied. 210 (50\%) were menopausal (Table 1). Descriptive statistics and normality test of the measured variables is showed in Table 2. Bivariate correlations between the variables are reported in Table 3.

\section{Hypothetical model testing and modified model}

For hypothetical model, the effect of health status $(\beta=0.103$, $\mathrm{p}=0.056)$, financial distress $(\beta=0.094, \mathrm{p}=0.076)$, and social support $(\beta=0.078, p=0.238)$ for happiness was not significant. Therefore, the 3 pathway were not selected as direct pathway, and hypothetical model was modified. Model fit of the modified model was satisfied; $\chi^{2}=102.108, \mathrm{GFI}=0.959, \mathrm{CMIN} /$ $\mathrm{DF}=2.917, \mathrm{RMSEA}=0.068, \mathrm{AGFI}=0.922, \mathrm{CFI}=0.977, \mathrm{SRMR}=$
0.0368 (Table 4). This study selected the modified model as the final model as shown in Figure 2.

In modified model, self-esteem was significant in direct ef-

Table 1. Participant characteristics $(\mathrm{N}=420)$

\begin{tabular}{|c|c|c|}
\hline Characteristic & Categories & $\mathrm{N}(\%)$ \\
\hline \multirow[t]{3}{*}{ Age (yr) } & $40-49$ & $171(40.7)$ \\
\hline & $50-59$ & $170(40.5)$ \\
\hline & $\geq 60$ & $79(18.8)$ \\
\hline \multirow[t]{4}{*}{ Duration of marriage $(\mathrm{yr})$} & 10 or less & $21(5.0)$ \\
\hline & $11-20$ & $105(25.0)$ \\
\hline & $21-30$ & $152(36.2)$ \\
\hline & More than 31 & $142(33.8)$ \\
\hline \multirow[t]{3}{*}{ Marital status } & Married & $392(93.3)$ \\
\hline & Divorce & $6(1.5)$ \\
\hline & Left alone & $22(5.2)$ \\
\hline \multirow[t]{3}{*}{ Education } & Middle school or less & $72(17.2)$ \\
\hline & High school & $200(47.6)$ \\
\hline & College or more & $148(35.2)$ \\
\hline \multirow[t]{2}{*}{ Religion } & Yes & $300(71.4)$ \\
\hline & No & $120(28.6)$ \\
\hline \multirow[t]{2}{*}{ Own occupation } & Yes & $284(71.4)$ \\
\hline & No & $136(28.6)$ \\
\hline \multirow[t]{3}{*}{ Satisfaction of marriage } & Satisfaction & $181(43.1)$ \\
\hline & Moderate & $187(44.5)$ \\
\hline & Dissatisfaction & $52(12.4)$ \\
\hline \multirow[t]{3}{*}{ Menses } & Regular & $164(39.0)$ \\
\hline & Irregular & $46(11.0)$ \\
\hline & Menopause & $210(50.0)$ \\
\hline
\end{tabular}

Table 2. Descriptive statistics of the measured variables $(\mathrm{N}=420)$

\begin{tabular}{|c|c|c|c|c|c|}
\hline Variables & Item & Categories & $\mathrm{M} \pm \mathrm{SD}$ & Skewness & Kurtosis \\
\hline Health status & 30 & & & & \\
\hline Physical health (X1) & 10 & $10-50$ & $28.07 \pm 8.09$ & 0.488 & -0.118 \\
\hline Mental health (X2) & 10 & $10-50$ & $23.53 \pm 7.71$ & 0.296 & 0.003 \\
\hline Social health (X3) & 10 & $10-50$ & $24.21 \pm 5.65$ & -0.182 & 0.234 \\
\hline Financial distress (X4) & 8 & $8-80$ & $55.33 \pm 15.56$ & -0.564 & 0.270 \\
\hline Social support & 12 & & & & \\
\hline Family (X5) & 4 & $4-28$ & $24.46 \pm 4.37$ & -0.730 & 0.203 \\
\hline Significant other (X6) & 8 & $8-56$ & $41.38 \pm 8.45$ & -0.231 & -0.398 \\
\hline Self-esteem (Y1) & 10 & $10-40$ & $31.20 \pm 3.93$ & 0.134 & -0.236 \\
\hline Positive thinking & 18 & & & & \\
\hline Subjective satisfaction (Y2) & 13 & $13-65$ & $47.51 \pm 8.07$ & 0.241 & -0.330 \\
\hline Goal pursuit (Y3) & 5 & $5-25$ & $19.25 \pm 3.27$ & -0.069 & -0.657 \\
\hline Happiness & 29 & & & & \\
\hline Positive factor (Y4) & 17 & $17-102$ & $70.33 \pm 11.20$ & 0.470 & 0.146 \\
\hline Negative factor (Y5) & 12 & $17-72$ & $48.96 \pm 7.98$ & 0.205 & -0.057 \\
\hline
\end{tabular}


fect and total effect from health status, financial distress and social support (Table 5). Positive thinking was significant in direct effect and total effect on health status, financial distress, social support, and self-esteem. Positive thinking was also significant indirectly from health status, financial distress, and social support. Happiness showed significant direct effect and total effect from positive thinking and self-esteem. The indirect effect and total effect from health status, finan- cial distress, and social support were significant. Happiness was explained by $82 \%$ through health status, financial distress, social support, self-esteem, and positive thinking.

\section{DISCUSSION}

In this study, we investigated factors influencing happiness of middle-aged women in Korea using health status, finan-

Table 3. Bivariate correlations among the measured variables $(\mathrm{N}=420)$

\begin{tabular}{|c|c|c|c|c|c|c|c|c|c|c|c|}
\hline & $\mathrm{X} 1$ & $\mathrm{X} 2$ & $\mathrm{X} 3$ & $\mathrm{X} 4$ & $\mathrm{X} 5$ & $\mathrm{X} 6$ & $\mathrm{Y} 1$ & $\mathrm{Y} 2$ & Y3 & Y4 & Y5 \\
\hline $\mathrm{X} 1$ & 1 & & & & & & & & & & \\
\hline $\mathrm{X} 2$ & $0.720^{*}$ & 1 & & & & & & & & & \\
\hline $\mathrm{X} 3$ & $0.616^{*}$ & $0.765^{*}$ & 1 & & & & & & & & \\
\hline $\mathrm{X} 4$ & $-0.368^{*}$ & $-0.448^{*}$ & $-0.343^{*}$ & 1 & & & & & & & \\
\hline $\mathrm{X} 5$ & $-0.320^{*}$ & $-0.463^{*}$ & $-0.406^{*}$ & $0.422^{*}$ & 1 & & & & & & \\
\hline X6 & $-0.342^{*}$ & $-0.506^{*}$ & $-0.453^{*}$ & $0.417^{*}$ & $0.767^{*}$ & 1 & & & & & \\
\hline Y1 & $-0.341^{*}$ & $-0.522^{*}$ & $-0.489^{*}$ & $0.463^{*}$ & $0.601^{*}$ & $0.613^{*}$ & 1 & & & & \\
\hline $\mathrm{Y} 2$ & $-0.414^{*}$ & $-0.555^{*}$ & $-0.493^{*}$ & $0.584^{*}$ & $0.536^{*}$ & $0.570^{*}$ & $0.693^{*}$ & 1 & & & \\
\hline $\mathrm{Y} 3$ & $-0.308^{*}$ & $-0.491^{*}$ & $-0.379^{*}$ & $0.410^{*}$ & $0.507^{*}$ & $0.532^{*}$ & $0.639 *$ & $0.670^{*}$ & 1 & & \\
\hline $\mathrm{Y} 4$ & $-0.307^{*}$ & $-0.465^{*}$ & $-0.413^{*}$ & $0.490^{*}$ & $0.495^{*}$ & $0.546^{*}$ & $0.695^{*}$ & $0.684^{*}$ & $0.568^{*}$ & 1 & \\
\hline Y5 & $-0.401^{*}$ & $-0.563^{*}$ & $-0.478^{*}$ & $0.466^{*}$ & $0.477^{*}$ & $0.499^{*}$ & $0.592^{*}$ & $0.569^{*}$ & $0.509^{*}$ & $0.542^{*}$ & 1 \\
\hline
\end{tabular}

${ }^{*} \mathrm{p}<0.01$. X1: Physical health, X2: Mental health, X3: Social health, X4: Financial distress, X5: Family, X6: Significant other, Y1: Self-esteem, Y2: Subject satisfaction, Y3: Goal pursuit, Y4: Positive factor, Y5: Negative factor

Table 4. Model fit of the modified model

\begin{tabular}{|c|c|c|c|c|c|c|c|c|c|}
\hline \multirow{2}{*}{ Model } & \multicolumn{3}{|c|}{$\operatorname{CMIN}\left(\chi^{2}\right)$} & \multirow{2}{*}{ CMIN/DF } & \multirow{2}{*}{ GFI } & \multirow{2}{*}{ AGFI } & \multirow{2}{*}{$\mathrm{CFI}$} & \multirow{2}{*}{ SRMR } & \multirow{2}{*}{ RMSEA } \\
\hline & $\chi^{2}$ & DF & $\mathrm{p}$ & & & & & & \\
\hline Hypothetical & 93.724 & 32 & $<0.001$ & 2.929 & 0.961 & 0.919 & 0.979 & 0.0324 & 0.068 \\
\hline Modified & 102.108 & 35 & $<0.001$ & 2.917 & 0.959 & 0.922 & 0.977 & 0.0368 & 0.068 \\
\hline
\end{tabular}

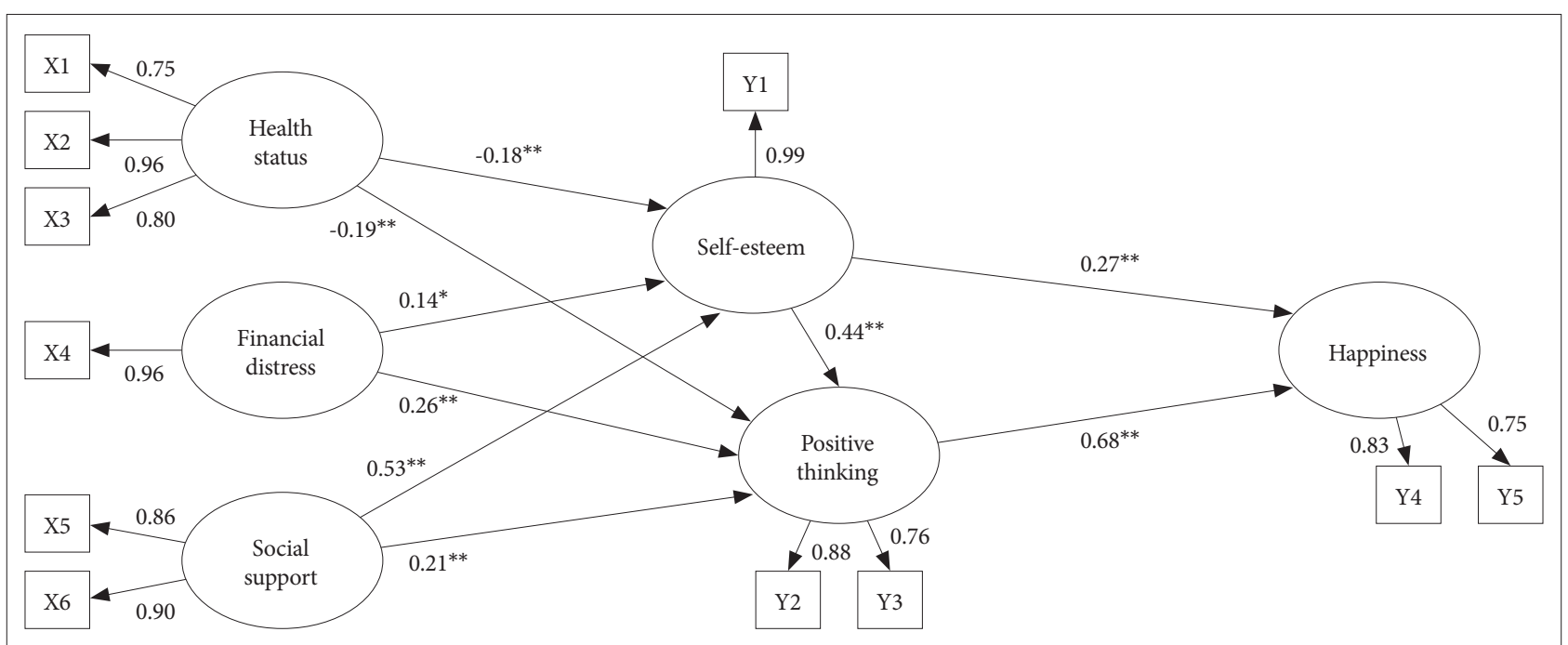

Figure 2. Final path diagram of the modified model. ${ }^{*} \mathrm{p}<0.01,{ }^{* *} \mathrm{p}<0.001 . \mathrm{X} 1$ : Physical health, $\mathrm{X} 2$ : Mental health, $\mathrm{X} 3$ : Social health, $\mathrm{X} 4$ : Financial distress, X5: Family, X6: Significant other, Y1: Self-esteem, Y2: Subject satisfaction, Y3: Goal pursuit, Y4: Positive factor, Y5: Negative factor 
Table 5. Direct, indirect and total effect of the modified model $(N=420)$

\begin{tabular}{|c|c|c|c|c|c|}
\hline & Paths & & Direct effect (p) & Indirect effect (p) & Total effect (p) \\
\hline Health status & $\longrightarrow$ & Self-esteem & $-0.181(<0.001)$ & & $-0.181(<0.001)$ \\
\hline Financial distress & $\longrightarrow$ & & $0.135(0.002)$ & & $0.135(0.002)$ \\
\hline Social support & $\longrightarrow$ & & $0.525(<0.001)$ & & $0.525(<0.001)$ \\
\hline Health status & $\longrightarrow$ & Positive thinking & $-0.194(<0.001)$ & $-0.080(0.008)$ & $-0.274(0.005)$ \\
\hline Financial distress & $\longrightarrow$ & & $0.255(<0.001)$ & $0.059(0.005)$ & $0.314(0.005)$ \\
\hline Social support & $\longrightarrow$ & & $0.206(<0.001)$ & $0.231(0.005)$ & $0.437(0.005)$ \\
\hline Self-esteem & $\longrightarrow$ & & $0.439(<0.001)$ & & $0.439(<0.001)$ \\
\hline Health status & $\longrightarrow$ & Happiness & & $-0.233(0.005)$ & $-0.233(0.005)$ \\
\hline Financial distress & $\longrightarrow$ & & & $0.248(0.005)$ & $0.248(0.005)$ \\
\hline Social support & $\longrightarrow$ & & & $0.434(0.005)$ & $0.434(0.005)$ \\
\hline Self-esteem & $\longrightarrow$ & & $0.266(<0.001)$ & $0.297(0.005)$ & $0.563(0.005)$ \\
\hline Positive thinking & $\longrightarrow$ & & $0.675(<0.001)$ & & $0.675(<0.001)$ \\
\hline
\end{tabular}

cial distress, social support, self-esteem, and positive thinking. This study made a structural model of their happiness based on Maslow's hierarchy of needs, which defined human desire achievement as basic needs, psychological needs, and self-fulfillment needs. This model consisted of three exogenous variables (health status, financial distress, and social support) and three endogenous variables (self-esteem, positive thinking, and happiness). The results showed that health, financial distress and social support affected happiness through the medication of self-esteem and positive thinking. Self-esteem and positive thinking were also found to affect happiness directly or indirectly. The results showed that the happiness of middle-aged women is gradually experienced from the basic needs to the self-fulfillment needs as Maslow's hierarchy of needs. Happiness was explained by $82 \%$ through health status, financial distress, social support, self-esteem, and positive thinking. Based on the results, we discussed five factors affecting the happiness of middle-aged women as follows.

Positive thinking has the greatest impact among the five factors influencing the happiness of middle-aged women in Korea. Positive thinking was one of the most influential factor of happiness. ${ }^{36}$ This results showed that attention should be paid to strengths and competences of middle-aged women, such as positive thinking. ${ }^{37}$ This means that the level of positive thinking of middle-aged women should be raised to improve the subjective satisfaction of life. ${ }^{30}$ Therefore, it is necessary to strengthen the positive competencies of middle-aged women in order to improve the positive thinking of middleaged women and to increase the happiness.

Self-esteem of middle-aged women affected happiness directly, and influenced happiness through positive thinking indirectly. Lyubomirsky et al ${ }^{38}$ indicate that self- esteem is the major predictor for happiness. In addition, the results of Diener and Seligman ${ }^{9}$ suggest that high level of self-esteem pro- motes individual's cognitive and emotional interpretation in a positive direction to promote happiness. The results of these previous studies are consistent with the results of this study. Therefore, to improve the self-esteem of middle-aged women, it is necessary to have a program to have the right self-image, and an intervention plan to confirm its effect.

Social support has no direct impact on happiness, but has an indirect effect on happiness through self-esteem and positive thinking. The higher the social support, the higher the selfesteem and positive thinking, and eventually the middle-aged woman's happiness is increased. Helgeson ${ }^{39}$ suggests that social relations and support relieve stress, and improve life positively. Diener et al. ${ }^{40}$ assert that a good relationship with family members and others is a positive factor that elevates selfesteem and positive thinking. Therefore, in order to promote the happiness of middle-aged women, it is necessary to consider the social support system of the family, and the surrounding people who can positively accept themselves. ${ }^{9}$

Financial distress doesn't directly affect happiness but it indirectly affects happiness through self-esteem and positive thinking. These results suggested that the direct influence of financial distress was reduced in the process of analyzing collectively the variables of self-esteem and positive thinking rather than the relationship between economic stress and happiness only. Lowering of financial distress leads to higher selfesteem and positive thinking, and eventually to a rise in the happiness of middle-aged women. In the case of economic level above average, this study is confirmed that desire such as self-development or self-acceptance acts as a stronger factor for happiness. ${ }^{41}$ Therefore, it is necessary to try to grasp and control the various variables affecting happiness so that middle-aged women can overcome the financial distress situation.

Health status has no direct effect on happiness, but it has an indirect effect on happiness through self-esteem and posi- 
tive thinking. In other words, if the health condition is good, self-esteem and positive thinking increase, and eventually it shows that the happiness of middle-aged women increases. The healthier people are, the more positive emotional expression and lively lives are maintained. ${ }^{42}$ In addition, the positive perception of the health level of the person increases the happiness by acting as a strong will to promote health. ${ }^{43}$ Therefore, middle-aged women should be provided with information on physical and psychological health of middle-aged women so that they can positively perceive their health condition, and intervention methods to educate health promotion methods that can be practiced continuously.

Based on the result of this study, to improve the happiness of middle-aged women, efforts should be made to improve the happiness by appropriately managing health condition, lowering financial distress, maintaining social support systematically and promoting self-esteem and positive thinking. In other words, self-esteem and positive thinking based on health status, financial distress, and social support are decisive factors for the happiness of middle-aged women. Therefore, middle-aged women need to develop various psychological and emotional programs that can enhance self-esteem and improve positive thinking.

The results of this study showed that health status, financial distress, social support, self-esteem, and positive thinking were important factors for the happiness of middle-aged women. We also found that health status, financial distress, social support, self-esteem, and positive thinking affected happiness. Therefore, it is necessary to develop nursing intervention education and programs that emphasize basic needs such as health status, financial distress, and social support in order to enhance the happiness of middle-aged women. In addition, for middle-aged women whose basic needs have been met, it is necessary to improve the positive thoughts and selfesteem, which are direct influences of happiness.

\section{Conflicts of Interest}

The authors have no potential conflicts of interest to disclose.

\section{Author Contributions}

Conceptualization: Su jin Kim, Myung-Haeng Hur. Data curation: Su jin Kim. Formal analysis: Su jin Kim, Myung-Haeng Hur. Investigation: Su jin Kim, Myung-Haeng Hur. Methodology: Su jin Kim, Myung-Haeng Hur. Project administration: Myung-Haeng Hur. Resources: Su jin Kim. Software: Su jin Kim. Supervision: Myung-Haeng Hur. Validation: Su jin Kim, Myung-Haeng Hur. Visualization: Su jin Kim. Writing_original draft: Su jin Kim, Myung-Haeng Hur. Writing_review \& editing: Su jin Kim, Myung-Haeng Hur.

\section{ORCID iDs}

Myung-Haeng Hur https://orcid.org/0000-0003-0523-8926

Su Jin Kim https://orcid.org/0000-0001-9266-1575

\section{REFERENCES}

1. Vaillant GE, Mukamal K. Successful aging. Am J Psychiatry 2001;158: 839-847.

2. Leonard R, Burns A. Turning points in the lives of midlife and older women: five-year follow-up. Aust Psychol 2006;41:28-36.

3. WHO. Women, Ageing and Health: A Framework for Action. Geneva: WHO Press; 2007.

4. Lachman ME, Agrigoroaei S. Promoting functional health in midlife and old age: long-term protective effects of control beliefs, social support, and physical exercise. PLoS One 2010;5:e13297.

5. Darling CA, Coccia C, Senatore N. Women in midlife: stress, health and life satisfaction. Stress Health 2012;28:31-40.

6. Cummins RA. Happiness is the right metric to measure good societal functioning. Society 2016;53:273-277.

7. Maslow AH. Motivation and Personality. 3 Ed. Boston: Longman; 1970.

8. Huppert FA, Abbott RA, Ploubidis GB, Richards M, Kuh D. Parental practices predict psychological well-being in midlife: life-course associations among women in the 1946 British birth cohort. Psychol Med 2010;40:1507-1518.

9. Diener E, Seligman MEP. Very happy people. Psychol Sci 2002;13:8184.

10. Seligman MEP. Authentic Happiness: Using the New Positive Psychology to Realize Your Potential for Lasting Fulfillment. New York: ATRIA; 2004.

11. Liu B, Floud S, Pirie K, Green J, Peto R, Beral V. Does happiness itself directly affect mortality? the prospective UK million women study. Lancet 2016;387:874-881.

12. Caprara GV, Steca P. Affective and social self- regulatory efficacy beliefs as determinants of positive thinking and happiness. Eur Psychol 2005; 10:275-286.

13. Rosenberg M. Society and the Adolescent Self-Image. New Jersey: Princeton University Press; 1965.

14. Kim KH, Kim HS, Park KS. The effects of family function, self-esteem, and loneliness on subjective health status in middle-aged women. J Korean Acad Soc Adult Nurs 2009;21:225-234.

15. Kim SA, Kim SY. The impacts of self-esteem and social support on mental health of the middle-age women. J Welfare Aged Instit 2011; 52:109-129.

16. Kim YS, Suzuki S, Kim JM. Practical use of THI questionnarie about healthy questionnaire. Korean J Indust Med 1979;18:18-28.

17. Satuf C, Monteiro S, Pereira H, Esgalhado G, Afonso RM, Loureiro M. The protective effect of job satisfaction in health, happiness, well-being and self- esteem. Int J Occup Saf Ergon 2018;24:181-189.

18. Arampatzi E, Burger MJ, Veenhoven R. Financial distress and happiness of employees in times of economic crisis. Appl Econ Lett 2015;22: 173-179.

19. Graham C, Chattopadhyay S. Gender and well-being around the world: Some insights from the economics of happiness. Int J Happ Develop 2013;1:212-232.

20. Zimet GD, Powell SS, Farley GK, Werkman S, Berkoff KA. Psychometric characteristics of the multidimensional scale of perceived social support. J Pers Assess 1990;55:610-617.

21. Peralta CF, Scaldanha MF. Can dealing with emotional exhaustion lead to enhanced happiness? the roles of planning and social support. Int J Work Health Organ 2017;31:121-144.

22. Tan CS, Krishnan SA, Lee QW. The role of self-esteem and social support in the relationship between extraversion and happiness: a serial mediation model. Curr Psychol 2017;36:556-564.

23. Easterlin RA. Does Economic Growth Improve the Human Lot? Some Empirical Evidence. In: David PA, Reder MW, Editors. Nations and Households in Economic Growth. New York: Academic Press, 1974, p. 89-125.

24. Ventegodt S, Merrick J, Andersen NJ. Quality of life theory III. Malsow revisited. Scientific World Journal 2003;3:1050-1057. 
25. Kim KH, Kim HS, Park KS. The effects of family function, self-esteem, and loneliness on subjective health status in middle-aged women. J Korean Acad Soc Adult Nurs 2009;29:225-234.

26. Kim MS, Kim HW, Cha CH, Im JY, Han YS. Exploration of the structure of happy life and development of the happy life scale among Korean adults. Korean J Health Psychol 2003;8:415-442.

27. Kang HJ. Procrastination, stress coping strategies, and subjective wellbeing of college students: the mediating effects of self-esteem. Discourse 2012;15:67-92.

28. Argyle M, Martin M, Crossland J. Happiness as a Function of Personality and Social Encounters. In: Forgas JP, Innes JM, Editors. Recent Advances in Social Psychology. Amsterdam: Elsevier, 1989, p.189-203.

29. Heo SY. Analysis of Ecological Variables Affecting Adolescent Happiness (Dissertation). Seoul: Sookmyung Women's University; 2009.

30. Kim HJ, Oh YH, Oh GS, Suh DW, Shin YC, Jung JY. Development and validation study of the positive thinking scale. Korean J Health Psychol 2006;11:767-784.

31. Jon BJ. Self-esteem: a test of its measurability. Yonsei J 1974;11:107-130.

32. Lee OS. The Relationship between the Rehabilitation Motive and Social Support Perceived by Spinal Cord Injury Patients (Master's Thesis). Seoul: The Catholic University of Korea; 2000.

33. Prawitz AD, Garman ET, Sorhaindo B, O'neill B, Kim J, Drentea P. Incharge financial distress/financial well-being scale: development, administration and score interpretation. J Fin Counsel Plan 2006;17:34-50.
34. Shin AK. A Study on the Economic Stress, Self-Esteem and Depression of Women Immigrants Married to Korean Men (Master's thesis). Seoul; Sookmyung Women's University; 2009.

35. Lim KH. A Study of Shifting Nurses' Health Conditions and Job Satisfaction (Master's Thesis). Seoul: Hanyang University; 2002.

36. Lee YJ. The efforts for becoming happy of college students. Asian J of Educ 2011;12:63-84.

37. Jeon HS, Lee HY. A study on subjective happiness, life satisfaction expectancy, mindfulness and social support of the marital middle-aged women. J Asian Women 2010;49:123-160.

38. Lyubomirsky S, Tkach C, Dimatteo MR. What are the differences between happiness and self-esteem. Soc Indic Res 2006;78:363-404.

39. Helgenson VS. Social support and quality of life. Qual Life Res 2003; 12:25-31.

40. Diener E, Suh EM, Lucas RE, Smith HL. Subjective well-being: three decades of progress. Psychol Bull 1999;125:276-302.

41. Easterlin RA. Happiness of women and men in later life: nature, determinants, and prospects. Adv Qual Life Theory Res 2003:13-25.

42. Danner DD, Snowdon DA, Friesen WV. Positive emotions in early life and longevity: findings from the nun study. Pers Soc Psychol 2001;80: 804-813.

43. Kim JH. The effects of happiness on health. Korean J Stress Res 2008; 16:123-141. 